\title{
Ergenlerde Madde Bağımlılığından Korunmaya İlişkin Özyeterlik ile Akran Baskısı, Kendini İfade Edebilme Becerisi ve Psikolojik Sağlamlık Arasındaki İlişki ${ }^{1}$
}

DOI: $10.26466 /$ opus.608229

\author{
Emrah Tilim* ${ }^{*}$ Mehmet Murat** \\ * Uzm. Psikolojik Danışman., Cemal Gürsel İlkokulu, Erzurum / Türkiye \\ E-Posta: emrahtilim@hotmail.com \\ ORCID: 0000-0002-7161-0004 \\ ** Doç. Dr. Gaziantep Üniversitesi, Eğitim Fakültesi, Gaziantep / Türkiye \\ E-Posta: mmurat6147@gmail.com \\ ORCID: $\underline{0000-0003-3946-7006}$
}

\begin{abstract}
Öz
Bu çalışmada ergenlerin madde bağımlılı̆̆ından korunma özyeterliklerinin akran zorbalı̆̆ına maruz kalma, duygular ifade etme ve psikolojik sağlamlık düzeyleri ile ilişkisi; bu ilişkilerinde yordayıcılık düzeyi incelenmiştir. Bu çalışma ilişkisel tarama türünde olup, araştırmanın örneklemi Gaziantep'te 2017-2018 eğitim-öğretim yılında öğrenim gören, seçkisiz örnekleme yöntemlerinden tabakalı örnekleme yöntemiyle belirlenmiş, 862 lise öğrencisinden oluşturulmuştur. Veri toplamak amacıyla katılımcılara "Akran Zorbalığım Belirleme Ölçeği", "Duyguları Ífade Ölçeğì", "Ergen Psikolojik Dayanıklılık Ölçeği" ve "Madde Bağımlılığından Korunma Özyeterlik Ölçeğgi" uygulanmıştır. Araştırmada anlamlılık düzeyi $p<.05$ ve $p<.01$ olarak kabul edilmiştir. Verilerin istatistiksel analizinde; Levene Homejenlik Testi, Pearson Momentler Çarpım Korelasyon Analizi, $t$ Testi ve Çoklu Doğrusal Regresyon Analizleri kullanılmıştır. Analizler sonucunda, ergenlerin madde bağımlılı̆̆ından korunma özyeterlikleri ile akran zorbalığına maruz kalmalarl, duygular ifade etme düzeyleri ve psikolojik dayanıklılı düzeyleri arasında anlaml ilişkilere; bu ilişkilerinde anlaml düzeyde yordayıcı olduğu sonucuna ulaşılmıştır. Bu çalışmanın bulgularına göre psikolojik sağlamlık düzeyleri artırılarak, kendini ifade etme ve olumsuz akran ilişkilerine karşı becerileri geliştirilerek çocuklar ve ergenler madde bağımlılı̆̆ riskine karşı korunabilir.
\end{abstract}

Anahtar Kelimeler: Ergenlik, Madde Bağımlılı̆̆ından Korunma Özyeterliği, Akran Zorbalı̆̆ı, Duyguları Ifade Etme, Psikolojik Sağlamlık

${ }^{1}$ Bu çalışma sorumlu yazarın aynı başılılı yüksek lisans tezinden çıkarılmıştır. 


\title{
A Relationship Between The Self-Efficacy About Adolescents' Avoidance Of Substance Abuse and The Peer Pressure, Self-Expression Skill, Resilience
}

$*$

\begin{abstract}
It was investigated the relationship of the self-efficacy about adolescents' avoidance of substance abuse with peer bullying, emotional expression, psychological resilience. Prediction level was also examined. This study is in the category of Correlational Survey Model, The sample of investigation was comprised of 862 high school students of 2017-2018 educational years. The sampling unit was determined with Stratified Sampling Method in Random Sampling Methods. "Peer Victimization Scale", "Emotional Expressing Questionnaire", "Adolescent Psychological Resilience Scale" and "Self-Efficacy for Protecting Adolescences from Substance Abuse Scale" were used. Meaning fulness was accepted as $p<.05$ and $p<.01$. In statistical data analysis; Levene Homogeneity Test and Pearson Correlation Coefficient Analysis, $t$-Test and Multiple Linear Regression Analysis were also carried out. There was a negative and significant relationship between self-efficacy about avoidance of substance abuse and being victim of peer bullying, whereas there was a positive and significant relationship between emotional expression and psychological resilience levels. Morever, it was reached that adolescents' exposure to peer bullying, emotional expression level and psychological resilience predicted the self-efficacy about avoidance of substance abuse. According to the findings of this study, children and adolescents can be protected against the risk of substance addiction by increasing their psychological robustness levels, developing self-expression and their skills against negative peer relationships.
\end{abstract}

Keywords: Adolescence, Peer Bullying, Expression of Emotions, Psychological Resilience, SelfEfficacy about Avoidance of Substance Abuse 


\section{Giriş}

Bağımlılık sorunu her geçen gün, daha fazla önemsenmesi gereken bir konu haline gelmektedir. Bağımlılıkla mücadele de kişinin bağımlı olmadan önce korunması ön plana çıkmakta, önleyici çalışmaların daha işlevsel ve ekonomik olduğ kabul edilmektedir. Önleme programları; erken yaşlarda madde kötüye kullanımının önüne geçmek, zararlı madde kullanımı ve buna bağlı ortaya çıkacak sorunları azaltmak, zararlı maddeler hakkında bilgilendirme, risklerin tanıtılması, sorumluluk duygusunun, karar verme ve problem çözme becerisinin geliştirilmesi, kaygının azaltılması, farklı bakış açısı kazanma, aktivitelere katılımın artırılması, iletişim becerisini artırma ve zararlı maddeye duyulan istekle baş etme becerisi kazandırmayı hedeflemektedir (Acar, 2006; Albayrak ve Balc1, 2014; EMCDDA, 2019; Oktay, 2017; Ögel, Taner, Eke ve Erol, 2004; Özada, 2015 s.56; Özbay vd., 2018 s.83; Özer, 2016; Pettigrew, Shin, Stein, Van Raalte, 2017; Spirito, Hernandez, Cancilliere, Graves ve Barnett, 2015; Yildiz, 2009).

Bağımlılık yapıcı maddeyle tanışma ve bağımlılık yapıcı maddeye maruz kalma, ilkokul seviyesine kadar düşmüştür (Balcı, Gülveren ve Balcı, 2015; Erdamar ve Kurupınar, 2014; Kaya, 2011; TBMM, 2008). Birçok çalışmada ise madde bağımlılığının, özellikle ergenlik döneminde, önemli bir risk faktörü olduğu bildirilmektedir (Çataloğlu, 2011; Çiydem, 2017; Gökçen, 2015; Kıran Esen, 2003; Korkut Owenn, 2011; Meclis Araştırma Raporu, 2008; ORGM, 2014; Uzun, 2017). Bundan dolayı ergenleri, madde bağımlılı̆̆ından koruyucu çalışmalar planlanmakta ve uygulanmaktadır. Ergenlerin madde bağımlılığında; akran etkisi ön plana çıkmakta, duygusal bağlamda beklentilerin olması ya da zayıf olunması ile psikolojik anlamda dayanıklı olunmaması ise risk oluşturmaktadır (Acar, 2006; Acar, 2017; Alikaşifoğlu ve Ercan, 2006; Alikaşifoğlu, 2008; Çataloğlu, 2011; Çiydem, 2017; Erdem, Eke, Ögel ve Taner, 2006; Gökçen, 2015; La Greca, Prinstein ve Fetter, 2001).

Whirter ve Acar (2000)'a göre arkadaş etkileşimine bağlı olarak, ergenlik döneminde kendini ifade etme becerisi önem kazanmaktadır. Ergenlik döneminde yaşanan problemlerin birçoğunun, özellikle duyguları ifade edememekten kaynaklandığını ifade etmektedirler (Akt. Dönmez, 2007). Ergenlerin yaşadıkları riskli durumlarla başedebilmeleri ise onların 
koruyucu faktörlere sahip olduklarını ve psikolojik sağlamlıklarını göstermektedir (Terzi, 2008; Doty, 2010 s.143; Algünerhan, 2017). Bireyin güçlü benlik algısı, yaşam becerilerine sahip olması, kızgınlık ve öfkesini ifade etme becerisi, problem-çatışma çözme becerisi, mizah ve empati becerisi madde kullanımına karşı koruyucu faktörlerdendir (Yıldız, 2009).

Türkiye'de ergenlerin pek çoğu madde kullanımından kaçınacak sosyal beceri ve bilişsel gelişim düzeyine sahip değildir. Ayrıca ülkemizde ergenlerin, madde bağımlılığından korunmada, duygusal anlamda zayıf oldukları; bağımlılık yapıcı maddeyi, olumsuz duyguları ile baş edebilmek ve hoşa giden duygular yaşayabilmek için kullandıkları bilinmektedir (Çataloğlu, 2011; Alikaşifoğlu ve Ercan, 2006).

Her yıl milyonlarca insan, sigaradan kurtulmak amaciyla profesyonel yardım talep etmektedir. Ancak bu kişilerin bir kısmı başarılı olurken, önemli bir kısmı "özyeterlik" inancının düşüklüğüne bağlı olarak başaramamaktadır (Burger, 2006, s.543). Çalışmalar, ergenlerde özyeterlik inancının en yaygın risk alma davranışlarından olan sigara içmeye ve uyuşturucu madde kullanmaya başlama ve devam etmeyi etkilediğini ortaya koymaktadır. Ergenlerin özyeterlik düzeylerinin yüksek olması sigara, alkol ve uyuşturucu madde kullanmayı reddetmelerini kolaylaştırmaktadır (Carpenter ve Howard, 2009; Li, Pentz, ve Chou, 2002). Özyeterlik; ergenlerin riskli davranışlarının azaltılmasında ve sosyal becerilerinin gelişiminde, maddeye başlama ve sürdürme davranışları üzerinde, sorun çözme becerilerinin artmasında, akran baskısı, akademik başarısızlık, fiziki ve ailesel sorunlarla baş etmelerinde önemli bir etkendir (Eker, Akkuş ve Kapısız, 2013; Singh ve Udainiya, 2009; Yardımcı ve Başbakkal, 2010).

Madde bağımlılığı; başta gençlerde olmak üzere, biyolojik, ruhsal ve sosyal çok boyutlu nedenlerden ortaya çıkmakta ve bu boyutlarda Türkiye'de ve dünya genelinde, ciddi sağlık sorunlarına yol açmaktadır (Gürol, 2008; Meclis Araştırma Raporu, 2008; TUBİM, 2012). Buna karşın ergenlerde, sigara ve alkol kullanımı genel anlamda azalmakta; ancak çoğu ülkenin, katı önlemlerine rağmen erişim kolaylığı nedeniyle ergenlerin sigara ve alkol kullanma oranları halen yüksektir (ESPAD, 2015; Törrönen, Roumeliotis, Samuelsson, Kraus ve Room, 2019). Alkol, tütün ve diğer uyuşturucular ile kumar, çocuk ve ergenlerde görülen internet, telefon ve oyun bağımlılığı arasında yüksek ilişki nedeniyle bir 
bağımlılıktan diğer bağımlılığa geçiş olabilmekte; bundan dolayı erken madde kullanımının önüne geçmek için bağımlılıkların tümü birlikte değerlendirilmelidir (ESPAD, 2015; TBMM Araştırma Komisyonu Raporu, 2018).

Her geçen gün, madde bağımlısı kişi sayısı artmaya devam etmekte ve psikoaktif madde literatürüne, bir yenisi daha eklenmektedir. Ülkeler çapında bağımlılıkla mücadeleye yapılan yatırımların hızı, bağımlılığın artışından geri kalmaktadır. Bir yandan bağımlılıkla tedavi yoluyla mücadele devam ederken diğer yandan bağımlı olmayanların riskli durumu devam etmektedir. Gelinen bu durum, madde bağımlılığı konusuna, daha çok önleyici çalışmalar kapsamında yaklaşılması gerektiğini göstermektedir (EMCDDA, 2019; Özer, 2016; TUBIM, 2014). Bununla birlikte; madde bağımlılarının tedavi ve topluma yeniden kazandırılması aşamasında harcanan emek ve maliyetin, önleme aşamasında harcanan emek ve maliyetten çok daha fazla olması, önleme ve erken müdahale çalışmalarının önemini ortaya koymaktadır (Albayrak ve Balcı, 2014).

\section{Çalışmanın Problemi}

$\mathrm{Bu}$ araştırmada, ergenlerin madde bağımlılığından korunmaya ilişkin özyeterlikleri ile akranları tarafından zorbalığa maruz kalmaları, duyguları ifade etme düzeyleri ve psikolojik sağlamlıkları arasındaki ilişki araştırılmıştır. Buna ek olarak ergenlerin; akranları tarafından zorbalığa maruz kalmalarının, duyguları ifade etme düzeylerinin ve psikolojik sağlamlıklarının, madde bağımlılığından korunmaya ilişkin özyeterliklerini yordayıp yordamadığı incelenmiştir.

$\mathrm{Bu}$ araştırmanın sonuçlarının, madde bağımlılığından korunmaya ilişkin özyeterliğe etki eden temel faktörlere 1şık tutacağ ${ }_{1}$ varsayılmaktadır. Akran ilişkileri, kendini ifade etme becerileri ve psikolojik sağlamlık gibi boyutların, ergenlerin madde bağımlılı̆̆ özyeterliklerinin düzeyini belirleyeceği düşünülmektedir. Risk grubunda yer alan ergenlerin, madde bağımlılığına karşı koruyucu özellikler ve kendini ifade etme becerisi geliştirmeleri amaçlanmaktadır. Dolayısıyla ergenler bağlamında, önleyici çalışmalara katkı sağlamanın yanında, bu alanda çalışan uzmanlara, eğitimcilere ve ebeveynlere yol gösterici sonuçlara ulaşmak hedeflenmektedir. 


\section{Yöntem}

Bu araştırma ilişkisel-tarama modellerine göre desenlenmiş betimsel bir çalışmadır.

\section{Çalışmanın Evren ve Örneklemi}

$\mathrm{Bu}$ araştırmanın evrenini Gaziantep ilinin merkez ilçeleri olan Şahinbey ve Şehitkâmil'de bulunan Anadolu liseleri ile mesleki ve teknik liselerde 9. 10. ve 11. sınıflara kayıtlı, 2017-2018 eğitim-öğretim yılında öğrenim gören, örgün eğitime tabi öğrenciler oluşturmaktadır. Araştırmanın örneklemi ise adı geçen merkezi ilçelerdeki her iki okul türünde öğrenim gören 862 öğrenciden oluşturulmuştur. Örneklem birimi, olasılıklı örnekleme yöntemlerinden tabakalı örnekleme yöntemiyle 13 farklı okuldan, her sinıf düzeyinden birer şube olmak üzere belirlenmiştir. Tabakalar sosyo-ekonomik düzey (düşük, orta ve yüksek) ile akademik seviyenin (düşük, orta ve yüksek) kesişme sağladığı durumlara göre belirlenmiş, sonrasında okul ve öğrenci seçimleri random olarak yapılmıştır.

\section{Veri Toplama Araçları}

Bu çalışmada Mynard ve Joseph (2000) tarafından geliştirilen, Gültekin ve Sayıl (2005) tarafından ise kültürümüze uyarlanan “Akran Zorbalığını Belirleme Ölçeği"; King ve Emmons (1990) tarafından geliştirilen, Kuzucu (2006) tarafından ise kültürümüze uyarlanan "Duyguları İfade Ölçeği", Bulut, Doğan ve Altundağ (2013) tarafından geliştirilen "Ergen Psikolojik Dayanıklılık Ölçeği" ile Eker, Akkuş ve Kapısız (2013) tarafından ergenlerin madde bağımlılığından korunmaya ilişkin özyeterlik algılarını ölçmek amacıyla geliştirilen "Madde Bağımlılığından Korunma Öz-yeterlik Ölçeği" kullanılmıştır.

\section{Verilerin İşlenmesi ve Analizi}

Veri toplama aşamasında 1078 katılımcı öğrenciye ulaşılmıştır. Tabachnick ve Fidell (2015)' in görüşüne uygun olarak, en fazla \% 2' ye kadar olan 
kayıp veriler ve boş bırakılan veriler aritmetik ortalama ile doldurulmuştur. Bu kapsamda veri setinden, toplam 63 katılımcıya ilişkin veriler, veri setinden çıkartılmıştır. Veri setinin homojen bir dağılım gösterip göstermediğini belirlemek için varyansların homojenliğini incelemeye imkan tanıyan Levene testi uygulanmıştır. Daha sonra homojen dağılım gösterdiği belirlenen verilerin normal dağılıma sahip olup olmadığını belirlemek için ise veri setinde tek değişkenli ve çok değişkenli normallik analizleri yapılmıştır. Bu kapsamda öncelikle Mahalanobis ve Cook's uzaklık değerleri ve basıklık-çarpıklık değerleri incelenerek uç değerler belirlenmiştir. Veri setinin uç değerlerden arındırılmasından sonra Komogorov-Smirnov analizleri ve histogram grafik görüntülemeleri ile veri setinin normalliği incelenmiş ve tek değişkenli ve çok değişkenli normalliğin sağlandığı tespit edilmiştir. Bu kapsamda toplam 153 katılımcıya ait veriler, veri setinden çıkarılmış ve veri setinde parametrik analizler yapılmasına olanak sağlanmıştır. Geriye kalan 862 katılımcıya ait veriler üzerinden araştırmanın sorularına cevap aranmıştır.

Verilerin analizinde SPSS-25.0 (Statistical Packet for The Social Science25.0) paket programı kullanılmıştır. Anlamlılık düzeyi $\mathrm{p}<0.05$ ve $\mathrm{p}<0.01$ olarak kabul edilmiştir. Verilerin analizi sürecinde Levene Homejenlik Testi ile Pearson Momentler Çarpım Korelasyon Analizi'nin yanı sıra t Testi ve Çoklu Doğrusal Regresyon Analizi yapılmıştır.

\section{Bulgular}

Bu bölümde sırasıyla ergenlerin madde bağımlılı̆̆ından korunma özyeterlikleri ile akran zorbalığına maruz kalmaları, duyguları ifade etme ve psikolojik dayanıklılık düzeyleri arasında ki ilişkilerin bulgularına yer verilmiştir. Sonrasında akran zorbalığı, duyguları ifade etme ve psikolojik dayanıklılık düzeylerinin alt boyutlarının; ergenlerin madde bağımlılığından korunmaya ilişkin özyeterliklerinin alt boyutlarını yordama düzeylerine ilişkin bulgulara yer verilmiştir.

Tablo 1.'de ergenlerin madde bağımlılı̆̆ından korunma özyeterlikleri ile akran zorbalığına maruz kalmaları arasında ki ilişki yer almaktadır. 
Tablo 1. Akran zorbalığına maruz kalma ile ergenlerin madde bağımlılı̆̆ından korunmaya ilişkin özyeterlikleri arasındaki ilişkiler

\begin{tabular}{lllll}
\hline Değişkenler & UMUD & BUMUD & UMYA & UMADO \\
\hline Korkutma &,$- 227^{* *}$ &,$- 202^{* *}$ &,$- 154^{* *}$ &,$- 110^{* *}$ \\
Alay &,$- 081^{*}$ &,$- 099^{* *}$ &,$- 137^{* *}$ &,$- 076^{*}$ \\
Açık saldırı &,$- 196^{* *}$ &,$- 194^{* *}$ &,$- 197^{* *}$ &,$- 107^{* *}$ \\
İlişkisel saldırı &,- 056 &,- 051 &,$- 137^{* *}$ &,- 022 \\
Eşyaya saldırı &,$- 118^{* *}$ &,$- 130^{* *}$ &,$- 133^{* *}$ &,$- 087^{*}$ \\
\hline
\end{tabular}

1. ${ }^{*} \mathrm{p}<.05, \quad{ }^{* *} \mathrm{p}<.01$

2. $\mathrm{UMUD}=$ Uyuşturucu/Uyarıcı Maddelerden Uzak Durma, BUMUD = Baskı Altındayken Uyuşturucu/Uyarıcı Maddelerden Uzak Durma, UMYA = Uyuşturucu/Uyarıcı Maddeler Konusunda Yardım Arama, UMADO = Uyuşturucu/Lyarııı Maddeler Konusunda Arkadaşına Destek Olma

Tablo 1. incelendiğinde; korkutma, alay, açık saldırı, ilişkisel saldırı ve eşyaya saldırı alt boyutları ile ergenlerin madde bağımlılığından korunmaya ilişkin özyeterlikleri arasında, negatif yönlü ve orta düzeyde anlamlı ilişkilerin olduğu görülmektedir.

Tablo 2.'de ergenlerin madde bağımlılı̆̆ından korunma özyeterlikleri ile duyguları ifade etme düzeyleri arasında ki ilişki yer almaktadır.

Tablo 2. Duyguları ifade etme düzeyleri ile ergenlerin madde bağımlılı̆̆ından korunmaya ilişkin özyeterlikleri arasındaki ilişsiler

\begin{tabular}{lllll}
\hline \multicolumn{1}{c}{ Değişkenler } & UMUD & BUMUD & UMYA & UMADO \\
\hline Olumlu duygu &, $094^{* *}$ &, 052 &, $101^{* *}$ &, $183^{*}$ \\
Yakınlık duygu &, $186^{* *}$ &, $148^{* *}$ &, $191^{* *}$ &, $210^{* *}$ \\
Olumsuz duygu &, 005 &, 008 &, $077^{*}$ &, $104^{* *}$ \\
\hline
\end{tabular}

Tablo 2. incelendiğinde, olumlu duygu, yakınlık duygusu ve olumsuz duygu alt boyutları ile ergenlerin madde bağımlılığından korunmaya ilişkin özyeterlikleri arasında, pozitif yönlü ve orta düzeyde anlamlı ilişkilerin olduğu görülmektedir.

Tablo 3.'de ergenlerin madde bağımlılı̆̆ından korunma özyeterlikleri ile psikolojik dayanıklılık düzeyleri arasında ki ilişki yer almaktadır. 
Tablo 3. Psikolojik dayanıklılık düzeyleri ile ergenlerin madde bă̆ımlılı̆̆ından korunmaya ilişkin özyeterlikleri arasındaki ilişkiler

\begin{tabular}{lllll}
\hline Değişkenler & UMUD & BUMUD & UMYA & UMADO \\
\hline Aile desteği &, $227^{* *}$ &, $222^{* *}$ &, $281^{* *}$ &, $105^{* *}$ \\
Akran desteği &, $157^{* *}$ &, $114^{* *}$ &, $109^{* *}$ &, $145^{* *}$ \\
Okul desteği &, $166^{* *}$ &, $110^{* *}$ &, $154^{* *}$ &, $136^{* *}$ \\
Uyum &, $178^{* *}$ &, $191^{* *}$ &, $201^{* *}$ &, $156^{* *}$ \\
Mücadele azmi &, $203^{* *}$ &, $165^{* *}$ &, $213^{* *}$ &, $159^{* *}$ \\
Empati &, $169^{* *}$ &, $122^{* *}$ &, $140^{* *}$ &, $178^{* *}$ \\
\hline
\end{tabular}

Tablo 3. incelendiğinde; aile desteği, akran desteği, okul desteği, uyum, mücadele azmi ve empati alt boyutları ile ergenlerin madde bağımlılığından korunmaya ilişkin özyeterlikleri arasında, pozitif yönlü ve orta düzeyde anlamlı ilişkilerin olduğu sonucuna ulaşılmıştır.

Tablo 4.'de akran zorbalığı, duyguları ifade etme ve psikolojik dayanıklılık düzeylerinin alt boyutlarının; ergenlerin madde bağımlılığından korunma özyeterliklerinin alt boyutu olan Uyuşturucu/Uyarıcı Maddelerden Uzak Durma alt boyutunu yordama düzeylerine ilişkin bulgulara yer verilmiştir.

Tablo 4. Uyuşturucu/uyarıcı maddelerden uzak durma alt boyutunun yordanmasına ilişkin çoklu regresyon analizi bulguları

\begin{tabular}{llllll}
\hline Değişken & B & Standart hata & $\beta$ & $\mathbf{t}$ & $\mathbf{p}$ \\
\hline Sabit & 35,794 & 2,644 & & 13,539 &, 000 \\
Olumlu duygu &, 037 &, 046 &, 031 &, 801 &, 424 \\
Yakınlık duygu &, 152 &, 065 &, 089 & 2,351 &, 019 \\
Olumsuz duygu &,- 082 &, 070 &,- 041 & $-1,163$ &, 245 \\
Akran destek &, 125 &, 084 &, 060 & 1,480 &, 139 \\
Aile destek &, 252 &, 070 &, 124 & 3,603 &, 000 \\
Okul destek &, 074 &, 084 &, 033 &, 885 &, 376 \\
Uyum &, 281 &, 140 &, 070 & 2,000 &, 046 \\
Mücadele azmi &, 166 &, 100 &, 066 & 1,671 &, 095 \\
Empati &, 200 &, 164 &, 049 & 1,215 &, 225 \\
Korkutma &,- 934 &, 260 &,- 142 & $-3,584$ &, 000 \\
Alay &, 199 &, 157 &, 049 & 1,268 &, 205 \\
Açık saldırı &,- 603 &, 276 &,- 093 & $-2,186$ &, 029 \\
İlişkisel saldırı &, 213 &, 148 &, 053 & 1,445 &, 149 \\
Kişisel eşya saldır1 &,- 193 &, 173 &,- 042 & $-1,110$ &, 267 \\
R=.38, R ${ }^{2}=.14$, F= 10.26, p $<.05$ & & & & \\
\hline
\end{tabular}

Tablo 4. incelendiğinde, ergenlerin psikolojik dayanıklılık ve duygularını ifade etme düzeylerinin madde bağımlılığından korunmaya ilişkin 
özyeterliliğin alt boyutlarından biri olan Uyuşturucu/Uyarıcı Maddelerden Uzak Durma alt boyutunu pozitif yönlü olarak yordadığı; buna karşın akran zorbalığına maruz kalma durumlarının, Uyuşturucu/Uyarıcı Maddelerden Uzak Durma alt boyutunu, negatif yönlü olarak yordadığ 1 görülmektedir $\left(\mathrm{R}=.38, \mathrm{R}^{2}=.14, \mathrm{~F}=10.26\right.$, $\left.\mathrm{p}<.05\right)$.

Tablo 5.'de akran zorbalığı, duyguları ifade etme ve psikolojik dayanıklılık düzeylerinin alt boyutlarının; ergenlerin madde bağımlılığından korunma özyeterliklerinin alt boyutu olan Baskı Altındayken Uyuşturucu/Uyarıcı Maddelerden Uzak Durma alt boyutunu yordama düzeylerine ilişkin bulgulara yer verilmiştir.

Tablo 5. Baskı altındayken uyuşturucu/uyarıcı maddelerden uzak durma alt boyutunun yordanmasına ilişkin çoklu regresyon analizi bulguları

\begin{tabular}{llllll}
\hline Değişkenler & $\mathbf{B}$ & Standart hata & $\boldsymbol{\beta}$ & $\mathbf{t}$ & $\mathbf{p}$ \\
\hline Sabit & 12,803 &, 894 & & 14,321 &, 000 \\
Olumlu duygu &,- 001 &, 016 &,- 003 &,- 064 &, 949 \\
Yakınlık duygu &, 041 &, 022 &, 072 & 1,878 &, 061 \\
Olumsuz duygu &,- 008 &, 024 &,- 012 &,- 344 &, 731 \\
Akran destek &, 035 &, 028 &, 051 & 1,224 &, 221 \\
Aile destek &, 094 &, 024 &, 139 & 3,984 &, 000 \\
Okul destek &,- 009 &, 028 &,- 012 &,- 314 &, 753 \\
Uyum &, 140 &, 047 &, 106 & 2,955 &, 003 \\
Mücadele azmi &, 042 &, 034 &, 050 & 1,253 &, 211 \\
Empati &, 027 &, 056 &, 020 &, 483 &, 629 \\
Korkutma &,- 238 &, 088 &,- 109 & $-2,703$ &, 007 \\
Alay &, 036 &, 053 &, 026 &, 676 &, 499 \\
Açık saldır1 &,- 201 &, 093 &,- 093 & $-2,152$ &, 032 \\
İlişkisel saldırı &, 087 &, 050 &, 065 & 1,745 &, 081 \\
Kişisel eşya saldır1 &,- 096 &, 059 &,- 062 & $-1,629$ &, 104 \\
R=.34, R2=.11, F= 8.16, p<.05 & & & & \\
\hline
\end{tabular}

Tablo 5. incelendiğinde, ergenlerin psikolojik dayanıklılık düzeylerinin madde bağımlılığından korunmaya ilişkin özyeterliliğin alt boyutlarından biri olan Baskı Altındayken Uyuşturucu/Uyarıcı Maddelerden Uzak Durma alt boyutunu pozitif yönlü olarak yordadığı; buna karşın akran zorbalığına maruz kalma durumlarının, Baskı Altındayken Uyuşturucu/Uyarıcı Maddelerden Uzak Durma alt boyutunu, negatif yönlü olarak yordadığı görülmektedir $\left(\mathrm{R}=.34, \mathrm{R}^{2}=.11, \mathrm{~F}=8.16, \mathrm{p}<.05\right)$. 
Tablo 6.'da akran zorbalığı, duyguları ifade etme ve psikolojik dayanıklılık düzeylerinin alt boyutlarının; ergenlerin madde bağımlılığından korunma özyeterliklerinin alt boyutu olan Uyuşturucu/Uyarıcı Maddeler Konusunda Yardım Arama alt boyutunu yordama düzeylerine ilişkin bulgulara yer verilmiştir.

Tablo 6. Uyuşturucu/uyarıcı maddeler konusunda yardım arama alt boyutunun yordanmasına ilişkin çoklu regresyon analizi bulguları

\begin{tabular}{llllll}
\hline Değişkenler & $\mathbf{B}$ & Standart hata & $\boldsymbol{\beta}$ & $\mathbf{t}$ & $\mathbf{p}$ \\
\hline Sabit & 4,554 & 1,322 & & 3,444 &, 001 \\
Olumlu duygu &, 015 &, 023 &, 025 &, 662 &, 508 \\
Yakınlık duygu &, 067 &, 032 &, 078 & 2,085 &, 037 \\
Olumsuz duygu &, 059 &, 035 &, 059 & 1,679 &, 093 \\
Akran destek &,- 007 &, 042 &,- 007 &,- 162 &, 872 \\
Aile destek &, 181 &, 035 &, 178 & 5,176 &, 000 \\
Okul destek &, 021 &, 042 &, 018 &, 488 &, 626 \\
Uyum &, 195 &, 070 &, 097 & 2,773 &, 006 \\
Mücadele azmi &, 098 &, 050 &, 077 & 1,965 &, 050 \\
Empati &, 108 &, 082 &, 053 & 1,312 &, 190 \\
Korkutma &,- 040 &, 130 &,- 012 &,- 304 &, 761 \\
Alay &,- 042 &, 078 &,- 020 &,- 530 &, 596 \\
Açık saldırı &,- 297 &, 138 &,- 091 & $-2,153$ &, 032 \\
Ilişkisel saldır1 &,- 096 &, 074 &,- 048 & $-1,302$ &, 193 \\
Kişisel eşya saldırı &,- 077 &, 087 &,- 033 &,- 887 &, 375 \\
R=.38, R2=.15, F= 10.75, p<.05 & & & & \\
\hline
\end{tabular}

Tablo 6. incelendiğinde, ergenlerin psikolojik dayanıklılık düzeylerinin madde bağımlılı̆̆ından korunmaya ilişkin özyeterliliğin alt boyutlarından biri olan Uyuşturucu/Uyarıcı Maddeler Konusunda Yardım Arama alt boyutunu pozitif yönlü olarak yordadığı; buna karşın akran zorbalığına maruz kalma durumlarının, Uyuşturucu/Uyarıcı Maddeler Konusunda Yardım Arama alt boyutunu, negatif yönlü olarak yordadığı görülmektedir $\left(\mathrm{R}=.38, \mathrm{R}^{2}=.15, \mathrm{~F}=10.75, \mathrm{p}<.05\right)$.

Tablo 7.'de akran zorbalığı, duyguları ifade etme ve psikolojik dayanıklılık düzeylerinin alt boyutlarının; ergenlerin madde bağımlılı̆̆ından korunma özyeterliklerinin alt boyutu olan Uyuşturucu/Uyarıcı Maddeler Konusunda Arkadaşına Destek Olma alt boyutunu yordama düzeylerine ilişkin bulgulara yer verilmiştir. 
Tablo 7. Uyuşturucu/uyarıcı maddeler konusunda arkadaşına destek olma alt boyutunun yordanmasına ilişkin çoklu regresyon analizi bulguları

\begin{tabular}{llllll}
\hline Değişkenler & $\mathbf{B}$ & Standart hata & $\boldsymbol{\beta}$ & $\mathbf{t}$ & $\mathbf{p}$ \\
\hline Sabit & 5,317 &, 942 & & 5,642 &, 000 \\
Olumlu duygu &, 045 &, 017 &, 109 & 2,752 &, 006 \\
Yakınlık duygu &, 056 &, 023 &, 094 & 2,438 &, 015 \\
Olumsuz duygu &, 027 &, 025 &, 040 & 1,099 &, 272 \\
Akran destek &, 024 &, 030 &, 034 &, 814 &, 416 \\
Aile destek &, 005 &, 025 &, 007 &, 206 &, 837 \\
Okul destek &, 028 &, 030 &, 036 &, 940 &, 348 \\
Uyum &, 126 &, 050 &, 091 & 2,514 &, 012 \\
Mücadele azmi &, 034 &, 035 &, 038 &, 947 &, 344 \\
Empati &, 120 &, 059 &, 085 & 2,048 &, 041 \\
Korkutma &,- 085 &, 093 &,- 037 &,- 919 &, 359 \\
Alay &,- 057 &, 056 &,- 040 & $-1,021$ &, 308 \\
Açık saldırı &,- 070 &, 098 &,- 031 &,- 717 &, 474 \\
İlişkisel saldırı &, 046 &, 053 &, 033 &, 875 &, 382 \\
Kişisel eşya saldırı &,- 079 &, 062 &,- 049 & $-1,282$ &, 200 \\
R=.32, R2=.10, F=6.99, p<.05 & & & & \\
\hline
\end{tabular}

Tablo 7. incelendiğinde, ergenlerin psikolojik dayanıklılık ve duygularını ifade etme düzeylerinin madde bağımlılığından korunmaya ilişkin özyeterliliğin alt boyutlarından biri olan Uyuşturucu/Uyarıcı Maddeler Konusunda Arkadaşına Destek Olma alt boyutunu pozitif yönlü olarak yordadığ görülmektedir $\left(\mathrm{R}=.32, \mathrm{R}^{2}=.10, \mathrm{~F}=6.99, \mathrm{p}<.05\right)$.

\section{Tartışma}

Ergenlerin akran zorbalığına maruz kalmaları ile madde bağımlılığından korunmaya ilişkin özyeterlikleri arasında negatif yönlü ve orta düzeyde anlamlı ilişkilere ulaşılmıştır. Bu çalışmanın sonuçlarıyla tutarlı olarak, madde bağımlılığında akran etkisinin ön planda olduğu, birçok çalışmada belirtilmektedir (Akpınar, Yoldaşcan ve Saatçi, 2006; Erdamar ve Kurupınar, 2014; Erdem, Eke, Ögel ve Taner, 2006; Genç, 2007; Gülmez, 2003; Hong vd., 2014; Karatay ve Kubilay, 2004; Kasap, 2015; Kaşıkçı, 2018; Kaya, 2011; Kıran Esen, 2003; Kırcan, 2006; Mayda vd., 2010; Sangalang, Tran, Ayers ve Marsiglia, 2016; Shepherd, Sutherland ve Newcombe, 2006; Simons Morton, Haynie, Crump, Eitel ve Saylor, 2001; Sucaklı, Keten, Çelik, Ölmez ve Yılmaz, 2015; Unlu, 2009; Ünlü ve Evcin, 2014). Bu etkinin kimi zaman akran zorbalığı, kimi zamanda akran baskısı şeklinde olduğu 
söylenebilir. Bu yaklaşımlardan farklı olarak; Törrönen, Roumeliotis, Samuelsson, Kraus ve Room (2019), gençlerin, önceki nesillere göre madde kötüye kullanımına zemin oluşturan akran baskısıyla daha kolay başa çıkabildiklerini savunmaktadır. Ermağan (2010); son yıllarda öğrencilerin madde kullanımına ilişkin yanlış inançlarının azaldığını, "Hayır!” deme becerilerinde artış olduğunu, madde kullanım sıklığında ve madde kullanma eğiliminde azalma olduğunu saptamıştır. Uludağlı ve Sayıl (2009)'a göre ise akranların olumlu veya olumsuz tutum ve davranışlarının ergenlerin üzerindeki etkisine ilişkin bulgular yanıltıcı olabilir. Bundan dolayı akran ilişkilerinin etkisi, aracı rol testinden geçirilmelidir.

$\mathrm{Bu}$ çalışmada ergenlerin duyguları ifade etme düzeyleri ile madde bağımlılığından korunmaya ilişkin özyeterlikleri arasında genel anlamda pozitif yönlü ve orta düzeyde anlamlı ilişkilere ulaşılmıştır. Akranlarla ilişki kurulması, bireye kendini ifade etme fırsatı sunmakta ve sosyal destek sağlamaktadır. Bu durum madde bağımlılığına karşı koruyucu etki oluşturmaktadır (Turhan, İnandı, Özer ve Akoğlu, 2011; Yılmaz ve Türkkahraman 2014).

Duygular; madde bağımlılığını başlatan, devam ettiren ve kronikleştiren bir faktördür. Bununla birlikte duygular bireyin bağımlılığ etmesinde önemlidir. Duygularını düzene koyamayan veya ifade edemeyen birey, madde kullanımına yönelip sonrasında bir kısır döngüye girebilmektedir (Arabacı, Dağlı ve Taş, 2018). Birey; stres, olumsuz duygu ve kaygısı ile baş etmek, rahatlamak, duygularını olumluya çevirmek ve ifade etmek, duygu kontrolü sağlamak, olumsuz duygularında hafiflik sağlamak, olumsuz durumlardan ve duygulardan kaçınmak, gerilimi azaltmak, iyi hissetmek ve haz almak için madde kullanımına yönelebilmektedir (Alikaşifoğlu ve Ercan, 2006; Arabacı, Dağlı ve Taş, 2018; Erbay, Oğuz, Yıldırım ve Fırat, 2016; Ögel, 2010). Ergenlerin iletişim ve girişimcilik becerilerinin geliştirilmesi, sosyal ilişkilerinin düzenlenmesi, yaşadıkları duyguları ve düşüncelerini yorumlama konusunda bilgilendirilmeleri madde kullanımının ve eğiliminin azaltılmasına katkı sağlayacaktır (Bülbül ve Odacı, 2018; Osmanoğlu, 2017; Potas, Erçetin, Açıalın, Güngör ve Soydas Akyol, 2018). Karaaslan (2017)'a göre ise ebeveynler; ergenlik çağında ki çocukları ile sosyal ilişki kurmalı, onların kendini ifade etme ve “Hayır!" deme becerisini geliştirmelidir. Ergenlerin 
daha çok ısrar nedeniyle ve rol-model alarak madde kullanmaya başlamaları, ebeveynlerin bu becerilerin geliştirilmesinde ki önemini ortaya koymaktadır.

Bu çalışmada, ergenlerin psikolojik dayanıklılık düzeyleri ile madde bağımlılığından korunmaya ilişkin özyeterlikleri arasında pozitif yönlü ve orta düzeyde anlamlı ilişkiler bulunmuştur. Psikolojik sağlamlığın değişimi daha çok; aile, okul, öğretmen ve akran desteği ile uyum sağlama becerisi, empati kurabilme ve mücadele azmi gibi faktörlerin etkisine bağlıdır (Bulut, Doğan ve Altundağ, 2013; Eminağaoğlu, 2006; Nguyen, Clark ve Belgrave, 2011). Bu faktörler bireysel, ailesel ve çevresel (Gizir, 2007) olarak da gruplandırılmaktadır. İlgili alan yazında; psikolojik dayanıklılığın belirleyicilerinden olan aile, akran ve okul desteğinin madde bağımlılığına olan etkisine daha sık rastlanmaktadır. Bununla birlikte özyeterlik algısının yüksek olması, geleceğe dönük umut düzeyinin ve mücadele etme azminin yüksek olmasının madde kullanımına yönelme riskini azalttı̆̆ bildirilmektedir (Alikaşifoğlu ve Ercan, 2006; Çataloğlu, 2011; Karatay ve Kubilay, 2004; Uludağlı ve Say1l, 2009; Uzun, 2017; Wills ve Yaeger, 2003). Buna karşın Gökçen (2015); madde kullanan veya kullanmayan üniversite öğrencilerinin psikolojik dayanıklılık düzeylerinin anlamlı düzeyde farklılaşmadığını tespit etmiştir. Yine Çırak (2016) yaptığı çalışmada, psikolojik dayanıklılığın alkol kullanımına istatistiksel anlamda bir etkisinin olmadığına ulaşmıştır.

Elde edilen bulgulara göre, akran zorbalığına maruz kalma, duyguları ifade etme ve psikolojik dayanıklılık düzeyi ergenlerin madde bağımlılığından korunmaya ilişkin özyeterliklerini yordamaktadır. Ergenlerin uyuşturucu/uyarıcı maddelerden uzak durmasında, yakınlık duygusunu ifade etmeleri, aile desteğini almaları, uyum sağlamaları, korkutma ve açık saldırıya uğramaları; baskı altındayken uyuşturucu/uyarıcı maddelerden uzak durmalarında aile desteğini almaları, uyum sağlamaları, korkutma ve açık saldırıya uğramaları önemli bir yer tutmaktadır. Aynı zamanda uyuşturucu/uyarıcı maddeler konusunda arkadaşına destek olmalarında olumlu ve yakınlık duygularını ifade etmeleri, uyum sağlamaları ve empati kurmaları; uyuşturucu/uyarıcı maddeler konusunda yardım aramalarında ise aile desteğini almaları, uyum sağlamaları, mücadele azmine sahip olmaları ve korkutma davranışlarına maruz kalmaları önemli bir yer tutmaktadır. 
Bu çalışmanın bulgularıyla tutarlı olarak Çırak (2016), duygusal anlamda dengesizlik ve dışadönük kişilik özelliklerinin alkol kullanımını yordadığı sonucuna ulaşmıştır. Zullig, Teoli ve Valois (2014)'nın lise öğrencilerinde yaptıkları çalışmada, ergenlerin duygusal özyeterlik düzeyleri azaldıkça alkol alma ve sigara içme davranışlarında artış olduğunu belirlemişlerdir. Özmen ve Kubanç (2013) ise ergenlerde yaptıkları çalışmada, bir kısım öğrencinin kendini ispatlamak amacıyla uyuşturucu madde kullanmaya başladıklarını tespit etmişdir. Ergenlerin bu davranışları çağlarına özgü olarak yorumlansa da, madde bağımlılığına karşı özyeterliklerinin gelişmediğini göstermektedir. Bununla birlikte yetiştirme yurdunda kalan ergenlerin, madde kullanımlarının yaygın olduğu tespit edilmiştir (Sucaklı, Keten, Çelik, Ölmez ve Yılmaz, 2015). Bu sonuçtan yola çıkarak yetiştirme yurdunda kalan ergenlerin, aile desteği ve sosyal destekten yoksun olmalarına bağlı olarak, madde kullanımına karşı özyeterliklerinin düşük olduğu söylenebilir.

Ergenlik döneminde ki öğrencilere, madde bağımlılığından korunmaya ilişkin eğitimlerin verilmesinin madde kullanımına karşı özyeterliklerini artırdığ 1 belirlenmiştir (Akkuş, Karaca, Şener, ve Ankaralı, 2017; Ramos, Sebastian, Murphy, Oreskovich ve Condon, 2017). Bülbül ve Odacı (2018) ise ergenlere aile, arkadaş ve öğretmen desteğini artıracak programların uygulanmasının, madde bağımlılığını ve eğilimini azaltacağını düşünmektedirler. Ailenin ilgisiz olması madde bağımlılığı riskini artırmaktadır (Özmen ve Kubanç, 2013). Buna ek olarak, Hong vd. (2014), ebeveynlerin katılım ve desteğinin yetersizliği, aile içi şiddete maruz kalma, olumsuz akran etkisi, okula ilişkin aidiyet duygusunda yetersizlik algısı, toplum şiddeti ve düzensizliği nedeniyle öğrenciler arasında zorbalık mağduru olma ile madde kötüye kullanım riskinin arttığını bildirmişlerdir.

Çevresel olumsuzluklar, özellikle okula ilişkin sorunlar, zorbalık ve uyuşturucu madde kullanımı gibi sorunların ortaya çıkmasına neden olmaktadır (Aküzüm ve Oral, 2015, s.6). Unlu (2009), madde kullanımı ile sosyal sermayenin (akran etkisi, aile bağları ve gençlik faaliyetleri) ilişkisini araştırmıştır. Madde kullanımı ile akran etkisinin pozitif, aile bağları ve gençlik faaliyetlerinin ise negatif ilişkili olduğunu tespit etmiştir. Yılmaz ve Sipahioğlu (2012), tek ebeveynle yaşayan ergenler için 
okulun ve öğretmenlerin sağladığı desteğin, yetişkine duyulan destek ihtiyacını karşılayabileceğini ifade etmiştir. Özellikle öğretmenler ilgi, destek ve cesaretlendirme ile bu ihtiyacı karşılayarak riskli durumlara karşı korumaktadır. Yine Peltzer (2009)'e göre okula bağlılık, ebeveyn gözetimi ve akran desteği sigara kullanımında koruyucu bir faktördür.

\section{Sonuç}

$\mathrm{Bu}$ çalışmanın bulgularına göre, ergenleri madde bağımlılı̆̆ına iten sebeplerin çok yönlü olduğu söylenebilir. Dolayısıyla madde bağımlılığını önleyici çalışmalara aile, akran etkisi, bireysel değişkenler, okul yaşamı ve diğer çevresel faktörler dahil edilebilir. Bu bağlamda çocuk ve ergenlere yönelik yapılacak madde bağımlılığıyla mücadele çalışmalarına; veli, öğrenci ve okul gibi paydaşların dahil edilmesi önemli görünmektedir.

Ebeveyn eğitimleriyle anne-baba tutumlarının iyileştirilmesinin, okul ve sınıf ortamında demokratik ortamın sağlanarak kendini ifade etme becerilerinin geliştirilmesinin, akranlarla ilişkilerin düzenlenmesinde ebeveynlerin rolünün artırılmasının ve öğretmenlerle işbirliğinin sağlanmasının; çocuk ve ergenlerin madde bağımlılı̆̆ından korunmaya ilişkin özyeterliklerini arttıracağı söylenebilir. Bununla birlikte, çocuk ve ergenlerin riskli yaşantılara karşı koruyucu becerilerinin artırılmasına yönelik, bireysel ve grup olmak üzere, okul psikolojik danışma çalışmalarının aktif hale getirilmesi sağlanabilir. Sonuç olarak çocuk ve ergenlerin, psikolojik sağlamlık düzeylerinin artırılması, kendini ifade etme ve olumsuz akran ilişkilerine karşı becerilerinin geliştirilmesiyle madde bağımlılığı riskine karşı korunmaları sağlanabilir. 


\title{
EXTENDED ABSTRACT
}

\section{A Relationship Between The Self-Efficacy About Adolescents' Avoidance Of Substance Abuse and The Peer Pressure, Self-Expression Skill, Resilience}

\author{
Emrah Tilim - Mehmet Murat \\ Ministry of National Education, Gaziantep University
}

In order to give up smoking, millions of people request for the professional help every year. Whereas some people succeed it, some of them don't succeed it because of low self-efficacy (Burger, 2006 s.543). Studies indicate that adolescents' self-efficacy affects cigarette smoking and drug use as a risk taking behavior. Adolescents' self-efficacy level makes adolescents' rejecting smoking, drinking alcohol and drug use easier (Carpenter ve Howard, 2009; Li, Pentz, ve Chou, 2002). Self-efficacy is an important factor to decrease adolescents' risky behaviors, to improve social skills, for the substance use, to increase problem solving skills, for peer pressure and academic failure, to cope with physical and family problems (Eker, Akkuş ve Kapısız, 2013; Singh ve Udainiya, 2009; Yardımcı ve Başbakkal, 2010).

In this study, the relationship between self-efficacy about avoidance of substance abuse and peer pressure, emotional expression, psychological resilience levels was also examined. Furthermore; according to the possible correlations, this study aimed to examine expression of emotions, adolescents' exposure to peer bullying and whether psychological resilience level predicts self-efficacy about avoidance of substance abuse or not.

The results of this research are assumed to illuminate the basic factors that affect self-efficacy about avoidance of substance abuse. It is considered that dimensions such as self-expression skills and psychological resilience determine the level of self-efficacy about avoidance of substance use. Adolescents at risk group are aimed to improve protective factors for substance use and self-expression skills. Thus, it is aimed to lead experts, educators and parents in this field for the adolescents besides contributing protective studies. 
The study group was comprised of 9th, 10th, 11th level students of vocational Anatolian high school in the district of Şehitkamil and Şahinbey in Gaziantep. 1078 students of 2017-2018 educational years were reached. The sampling unit was determined with stratified sampling method in random sampling methods. Stratified sampling method; it provides the subgroups comprising the populations to be represented within the sampling in accordance with their impotance. In the first step, it was cancelled because it was determined that 63 paticipants answered a scale or some scales randomly or didn't answer them. In the second step, in the normality analysis of data set, 153 participants were excluded. The last 862 participants' answers were subjected to analysis. "Peer Victimization Scale", "Emotional Expressing Questionnaire", "Adolescent Psychological Resilience Scale" and "Self-Efficacy for Protecting Adolescences from Substance Abuse Scale" were carried out on the sampling group. Correlational analyses were carried out and Multiple Linear Regression was analysed in order to determine the predicting relationships.

In this study; there was a negative and significant relationship between self-efficacy about avoidance of substance abuse and being victim of peer bullying, whereas there was a positive and significant relationship between emotional expression and psychological resilience levels. Morever; it was reached that adolescents' exposure to peer bullying, emotional expression level and psychological resilience predicted the self-efficacy about avoidance of substance abuse.

Results: (1) It was reached that there is midlevel, negative and significant relationship between the self-efficacy about adolescents'avoidance of substance abuse and being victim of peer bullying. It can be considered that adolescents' exposure to peer bullying or peer pressure will lower the self-efficacy about adolescents' avoidance of substance abuse. (2) It was reached that there is midlevel, positive and significant relationship between emotional expression level and the self-efficacy about adolescents'avoidance of substance abuse. (3) It was reached that there is midlevel, positive and significant relationship between the psychological resilience level and the self-efficacy about adolescents' avoidance of substance abuse. Therefore, it can be considered that adolescents' emotional expression level and high psychological resilience level will raise the selfefficacy about adolescents'avoidance of substance abuse. 
It was concluded that adolescents feeling under pressure have low selfefficacy. According to the positive association between the self-efficacy about adolescents' avoidance of substance abuse and the emotional expression, psychological resilience levels, Adolescents' self-expression skills and studies in different fields such as personal, family and school life, peer relations that raise their psychological resilience may be planned.

It can be said that drug addiction prevention studies will increase the self-efficacy about avoidance from substance addiction. As a result; in order to increase the self-efficacy of adolescents' avoidance of substance addiction, coping with the influence of peers and expressing skills of themselves should be developed, and the level of psychological resilience should be increased. It can be ensured that children and adolescents aiming at increasing the level of psychological resilience, expressing themselves and developing skills against negative peer relationships can be protected against the risk of substance abuse. In this context, for the efforts to fight against drug addiction target towards children and adolescents; it seems important to involve stakeholders such as parents, students and schools.

\section{Kaynakça / References}

Acar, M. (2006). Türkiye'de madde bağımlılığı ve gençlik. Yayınlanmamış yüksek lisans tezi, Kırıkkale Üniversitesi Sosyal Bilimler Enstitüsü, Kırıkkale. Acar, S. (2017). Sigara içen ve sigara içmeyen bireylerin psikolojik dayanıklllk ve stresle başa çıkma tutumları açısından karşılaştırılması. Yayınlanmamış yüksek lisans tezi, Ege Üniversitesi Sağlık Bilimleri Enstitüsü, İzmir.

Akkuş, D., Karaca, A., Şener, D. K. ve Ankaralı, H. (2017). Lise öğrencileri arasında sigara ve alkol kullanma sıklığı ve etkileyen faktörler. Anadolu Kliniği, 22(1), 36-45. DOI: 10.21673/anadoluklin.245632

Akpınar, E., Yoldaşcan, E., ve Saatçi, E. (2006). The smoking prevalence and the determinants of smoking behaviour among students in Cukurova University, Southern Turkey. West Indian Medical Journal, 55(6), 414419.

Aküzüm, C. ve Oral, B. (2015). Yönetici ve öğretmen görüşleri açısından okullarda görülen en yaygın şiddet olayları, nedenleri ve çözüm önerileri. EKEV Akademi Dergisi, 61(61), 1-30. 
Albayrak, S. ve Balcı, S. (2014). Gençlerde madde bağımlılığı ve önlenmesi. Hemşirelikte Eğitim ve Araştırma Dergisi, II(2), 30-37.

Algünerhan, R. G. (2017). 12-14 yaşındaki ergenlerde algilanan anne baba tutumları benlik algisı ve psikolojik sağlamlı. Yayınlanmamış yüksek lisans tezi, Nişantaşı Üniversitesi Sosyal Bilimler Enstitüsü, İstanbul.

Alikaşifoğlu, M. (2008). Ergenlerde davranışsal sorunlar. İ.Ü. Cerrahpaşa Tip Fakültesi Sürekli Tip Etkinlikleri, Adolesan Să̆ğı̆̆ 2 2, Sempozyum Dizisi No: 63. Mart 2008 S.55-59.

Alikaşifoğlu, M. ve Ercan, O. (2006). Ergenlerde madde kullanımı. Türkiye Klinikleri Pediatrik Bilimler Dergisi, 2(5), 76-83.

Arabacı, L. B., Dağlı, D. A. ve Taş, G. (2018). Madde Kullanım Bozukluklarında Duygu Düzenleme Güçlüğü ve Hemşirelerin Rol ve Sorumlulukları. Bağımlılık Dergisi, 19(1), 10-16.

Balcı, S., Gülveren, H. ve Balcı, M. (2015). Madde bağımlılığı konulu kamu spotlarının lise öğrencilerince değerlendirilmesi. Turkish Studies International Periodical For The Languages. 10(6), 287-306.

Bülbül, K. ve Odacı, H. (2018). Lise öğrencilerinde umutsuzluk, bağlanma stili ve aile yapısının madde kullanma eğilimini yordama gücü. Klinik Psikiyatri Dergisi, 21(4), 360-369.

Bulut, S., Doğan, U. ve Altundağ, Y. (2013). Adolescent Psychological Resilience Scale: Validity and Reliability Study. Contemporary Psychology, Suvremena Psihologija, 16(1), 21-32.

Burger, J. M. (2006). Kişilik (İ. D. Erguvan Sarığlu, Çev.). İstanbul: Kaknüs Yayınları.

Carpenter, C. M. ve Howard, D. (2009). “Development of a drug use resistance self-efficacy (DURSE) scale." American Journal of Health Behavior, 33(2), 147-157.

Çataloğlu, B. (2011). Madde Kullanan ve Kullanmayan Ergenlerin Psikolojik Sağlamlık ve Aile İşlevleri Açısından Karşılaştırılması. Yayınlanmamış yüksek lisans tezi, Dokuz Eylül Üniversitesi Eğitim Bilimleri Enstitüsü, İzmir.

Çırak, T. D. (2016). Psikolojik dayanıklılık ve kişilik özelliklerinin alkol kullanımına etkisi. Yayınlanmamış yüksek lisans tezi, Beykent Üniversitesi Sosyal Bilimler Enstitüsü, İstanbul.

Çiydem, E. (2017). Hemşirelik öğrencilerinde riskli davranışlar, akran baskısı ve psikolojik dayanıklılık. Yayınlanmamış Yüksek lisans tezi, İstanbul Üniversitesi Sağlık Bilimleri Enstitüsü, İstanbul. 
Dönmez, M. M. (2007). Meslek lisesi öğrencilerinin atılganlık düzeylerine göre yaşam doyumu ve duyguları ifade etme eğilimlerinin karşılaştırılması. Yayınlanmamış yüksek lisans tezi, Ankara Üniversitesi Eğitim Bilimleri Enstitüsü, Ankara.

Doty, B. (2010). The construct of resilience and its application to the context of political violence. Pursuit-The Journal of Undergraduate Research at the University of Tennessee, 1(1), 137-154.

Eker, F., Akkuş, D. ve Kapısız, Ö. (2013). Ergenler Için Madde Bağımlılı̆̆ından Korunma Özyeterlik Ölçeği'nin geliştirilmesi ve psikometrik değerlendirilmesi. Psikiyatri Hemşireliği Dergisi, 4(1), 7-12.

EMCDDA, (2019). Avrupa uyuşturucu raporu 2019: Eğilimler ve gelişmeler, Avrupa Toplulukları Resmi Yayınlar Bürosu, Lüksemburg

Eminağaoğlu, N. (2006). Güç koşullarda yaşayan sokak çocuklarında dayanıklılık (sağlamlık). Yayımlanmamış doktora tezi, Ege Üniversitesi Sosyal Bilimler Enstitüsü, İzmir.

Erbay, E., Oğuz, N., Yıldırım, B. ve Fırat, E. (2016). Alkol ve madde bağımlılığ olan bireylerin başa çıkma tutumları. Türkiye Sosyal Araştırmalar Dergisi, (3), 597-609.

Erdamar, G. ve Kurupınar, A. (2014). Ortaöğretim öğrencilerinde görülen madde bağımlılığı alışkanlığı ve yaygınlığı: Bartın ili örneği. Sosyal Bilimler Dergisi, 16(1), 65-84.

Erdem, G., Eke, C. Y., Ögel, K. ve Taner, S. (2006). Lise öğrencilerinde arkadaş özellikleri ve madde kullanımı. Journal of Dependence, 7, 111-116.

Ermağan, E. (2010). İlköğretim okullarında uygulanan madde kullanımın önleme programlarmın bilgi ve beceri düzeylerine etkisinin değerlendirilmesi. Yayınlanmamış yüksek lisans tezi, İstanbul Üniversitesi Adli Tıp Enstitüsü, İstanbul.

ESPAD, (2015). $\quad$ www.espad.org/sites/espad.org/files/ESPAD_report_2015.pdf (Erişim: 18.06.2018)

Genç, G. (2007). Genel liselerde akran zorbalı̆̆l ve yönetimi. Yayımlanmamış Yüksek Lisans Tezi, İnönü Üniversitesi, Sosyal Bilimler Enstitüsü, Malatya.

Gizir, C. A. (2007). Psikolojik sağlamlık, risk faktörleri ve koruyucu faktörler üzerine bir derleme çalışması. Türk Psikolojik Danışma ve Rehberlik Dergisi, 3(28), 113-128. 
Gökçen G. (2015). Madde kullanan ve kullanmayan üniversite öğrencilerinin psikolojik dayanıklllık düzeylerinin incelenmesi. Yayınlanmamış yüksek lisans tezi, Akdeniz Üniversitesi Eğitim Bilimleri Enstitüsü, Antalya.

Gülmez, G. (2003). Sosyoekonomik düzeyi farklı iki lisede madde kullanma durumu ve etkileyen faktörlerin belirlenmesi. Yayınlanmamış bilim uzmanlığ tezi, Hacattepe Üniversitesi Sağllk Bilimleri Enstitüsü, Ankara.

Gültekin, Z. ve Sayıl, M. (2005). Akran Zorbalığını Belirleme Ölçeği geliştirme çalışması. Türk Psikologlar Derneği, Türk Psikoloji Yazıları, 8(15) 47-61.

Gürol, D. T. (2008). Madde bağımlılığı açısından riskli adolesanlar. İstanbul Üniversitesi Cerrahpaşa Tıp Fakültesi Sürekli Tıp Eğitimi Etkinlikleri, Adölesan Sağhı̆̆ı II Sempozyum Dizisi, 63, 65-68.

Hong, J. S., Davis, J. P., Sterzing, P. R., Yoon, J., Choi, S. ve Smith, D. C. (2014). A conceptual framework for understanding the association between school bullying victimization and substance misuse. American Journal Of Orthopsychiatry, 84(6), 696-710.

Karaaslan, A. (2017). Çocuk ve ergenlerde uçucu madde bağımlılığını etkileyen psikososyal sebepler: Olgu sunumu. Hacettepe Üniversitesi Sağllk Bilimleri Fakültesi Dergisi, 4(2), 1-11.

Karatay, G. ve Kubilay, G. (2004). Sosyoekonomik düzeyi farklı iki lisede madde kullanma durumu ve etkileyen faktörlerin belirlenmesi. Hemşirelikte Araştırma Geliştirme Dergisi, 1(2), 52-70.

Kasap, H. (2015). 15-17 yaş grubu ergenlerde sosyal destek, okul başarısı ve aile yapısının madde bağımlılığına karşı koruyucu etkisi. Yayınlanmamış yüksek lisans tezi, Üsküdar Üniversitesi Sosyal Bilimler Enstitüsü, İstanbul.

Kaşıkçı, S. B. (2018). Madde bağımlısı olan ve olmayan 17-18 yaş arası ergenlerin algıladıkları ebeveyn kabul-reddi ve akran baskısının değerlendirilmesi. Yayımlanmamış yüksek lisans tezi, Celal Bayar Üniversitesi Sağlık Bilimleri Enstitüsü, Manisa.

Kaya, Z. (2011). Madde kullanan ve kullanmayan ergenlerin kişilik özellikleri ve benlik saygısı açısından karşılaştırılması. Yayınlanmamış doktora tezi, Dokuz Eylül Üniversitesi Eğitim Bilimleri Enstitüsü, İzmir.

Kıran Esen, B. (2003). Akran baskısı, akademik başarı ve yaş değişkenlerine göre lise öğrencilerinin risk alma davranışının yordanması. Hacettepe Üniversitesi Ĕ̆itim Fakültesi Dergisi, 24(24), 79-85. 
Kircan, S. (2006). The relationship between peer pressure, internal versus external locus of control and adolescent substance use. Yüksek lisans tezi, Boğaziçi Üniversitesi Sosyal Bilimler Enstitüsü, İstanbul.

Korkut Owen, F. (2011). Okul temelli önleyici rehberlik ve psikolojik danışma. (3. Baskı). Ankara: Anı Yayıncılık.

Kuzucu, Y. (2006). Duyguları fark etmeye ve ifade etmeye yönelik bir psikoeğitim programının üniversite öğrencilerinin duygusal farkındalık düzeylerine, duyguları ifade etme eğilimlerine, psikolojik ve öznel iyi oluşlarına etkisi. Yayınlanmamış doktora tezi, Ankara Üniversitesi Eğitim Bilimleri Enstitüsü, Ankara.

La Greca, A. M., Prinstein, M. J. and Fetter, M. D. (2001). Adolescent peer crowd affiliation: Linkages with health-risk behaviors and close friendships. Journal of pediatric psychology, 26(3), 131-143.

Li, C., Pentz, M. A. and Chou, C. P. (2002). Parental substance use as a modifier of adolescent substance use risk. Addiction, 97(12), 1537-1550.

Mayda, A. S., Gerçek, Ç. G., Gümüş, G., Demir, S., Deniz, M., Sürücü, Z. P. ve Taner, H. (2010). Düzce Üniversitesi Orman Fakültesi öğrencilerinde sigara, alkol ve madde kullanımı sıklığı ve kullanmaya başlama nedenleri. Düzce Medical Journal, 12(3), 7-14.

Meclis Araştırma Raporu, (2008). Uyuşturucu başta olmak üzere madde bağımlılı̆̆ı ve kaçakçılı̆̆ı sorunlarının araştırılarak alınması gereken önlemler. TBMM, Ankara, 323, Syf.7-13.

Nguyen, A. B., Clark, T. T. ve Belgrave, F. Z. (2011). Empathy and drug use behaviors among African-American adolescents. Journal of Drug Education, 41(3), 289-308. https://doi.org/10.2190/DE.41.3.d

Ögel K. (2010). Madde kullanımı ve bağımlılı̆̆ı nedenleri. http://www.ogelk.net/Dosyadepo/etyoloji.pdf (Erişim: 08.03.2019)

Ögel, K., Taner, S., Eke, C. Y. ve Erol, B. (2004). Madde bağımlılığını önlemede öğretmen ve ebeveyn eğitimlerinin etkinliğinin değerlendirilmesi. Anadolu Psikiyatri Dergisi, 5(4), 213-221.

Oktay, İ. (2017). Lise öğrencilerinde uyuşturucu madde bă̆ımlılı̆̆ının sebepleri: Bursa ili Mustafa Kemalpaşa ilçesi örneği. Yayınlanmamış yüksek lisans tezi, Aksaray Üniversitesi Sosyal Bilimleri Enstitüsü, Aksaray.

ORGM (Özel Eğitim ve Rehberlik Hizmetleri Genel Müdürlüğü), (2014). https://orgm.meb.gov.tr/meb_iys_dosyalar/2014_09/18112817_genelge.pdf (Erişim: 14.12.2018) 
Osmanoğlu, D. E. (2017). Üniversite öğrencilerinin içme nedenleri ve madde bağımlılığından korunma özyeterlik davranışlarının belirlenmesi ve içme nedenlerine dair görüşleri. Atatürk Üniversitesi Kazım Karabekir Eğitim Fakültesi Dergisi, 35, 198-222.

Özada, A. (2015). Madde bağımlılığını önlemeye yönelik okul odaklı müdahale. Suç Kongresi. https://www.researchgate.net/publication/291165608

Özbay, Y., Yılmaz, S., Büyüköztürk, Ş., Aliyev, R., Tomar, İ. H., Eşici, H., Yancar, C. ve Akyıldız, F. D. (2018). Madde bağımlılı̆̆ı: Temiz bir yaşam için bireyin güçlendirilmesi. Addicta: The Turkish Journal on Addictions, 5, 81-130. http://dx.doi.org/10.15805/addicta.2018.5.1.0001

Özer, İ. N. (2016). Madde bağımlılarının maddeye başlama sebeplerinin tespiti ve önleyici hizmetlerin geliştirilmesi. Yayınlanmamış yüksek lisans tezi, Polis Akademisi Güvenlik Bilimleri Enstitüsü, Ankara.

Özmen, F. ve Kubanç, Y. (2013). Liselerde madde bağımlılığı, mevcut durum ve önerilere ilişkin okul müdürleri ve öğretmenlerin bakış açıları. Electronic Turkish Studies, 8(3), 357-382.

Peltzer, K. (2009). prevalence and correlates of substance use among school children in six african countries. International Journal of Psychology, 44 (5), 378-386.

Pettigrew, J., Shin, Y., Stein, J. B. ve Van Raalte, L. J. (2017). Family communication and adolescent alcohol use in Nicaragua, Central America: A test of primary socialization theory. Journal of Family Communication, 17(1), 33-48.

Potas, N., Erçetin, Ş. Ş., Açıkalın, Ş. N., Güngör, H. ve Soydas Akyol, E. (2018). A comprehensive study on addiction: 3D scale on youth. Addicta: The Turkish Journal on Addictions. Advance online publication. http://dx.doi.org/10.15805/addicta.2018.5.3.0022

Ramos, M. M., Sebastian, R. A., Murphy, M., Oreskovich, K. ve Condon, T. P. (2017). Adolescent substance use: Assessing the knowledge, attitudes, and practices of a school-based health center workforce. Substance abuse, 38(2), 230-236.

Sangalang, C. C., Tran, A. G., Ayers, S. L. ve Marsiglia, F. F. (2016). Bullying among urban Mexican-heritage youth: Exploring risk for substance use by status as a bully, victim, and bully-victim. Children and youth services review, 61, 216-221. 
Shepherd, J. P., Sutherland, I. ve Newcombe, R. G. (2006). Relations between alcohol, violence and victimization in adolescence. Journal of Adolescence, 29(4), 539-553.

Simons Morton, B., Haynie D. L., Crump, A. D., Eitel, P. ve Saylor, K. E. (2001). Peer and parent influences on smoking and drinking among early adolescents. Health, Education ve Behavior, 28(1), 95-107.

Singh, B. ve Udainiya, R. (2009). Self-efficacy and well-being of adolescents. Journal of The Indian Academy of Applied Psychology, 35(2), 227-232.

Spirito, A., Hernandez, L., Cancilliere, M. K., Graves, H. ve Barnett, N. (2015). Improving parenting and parent-adolescent communication to delay or prevent the onset of alcohol and drug use in young adolescents with emotional/behavioral disorders: A pilot trial. Journal of child ve adolescent substance abuse, 24(5), 308-322.

Sucaklı, M. H., Keten, H. S., Çelik, M., Ölmez, S. ve Yılmaz, A. (2015). Yetiştirme yurdunda kalan çocuk ve ergenlerde sigara, alkol ve madde kullanımı. Konuralp Tıp Dergisi, 7(1), 23-27.

Tabachnick, B. G. ve Fidell, L. S. (2015). Çok değişkenli istatistiklerin kullanımı (Baloğlu, M., Çev.). Ankara: Nobel Yayın Dağıtım.

TBMM Araştırma Komisyonu Raporu (2008). Madde kullanımı ve bağımlılığı ile kaçakçılığının önlenmesi alanlarında tespit edilen sorunlar ve çözüm önerileri. http://www.tbmm.gov.tr/docs/madde-_kullanimi_ ve_bagimliligi.pdf (Erişim Tarihi: 14.05.2018)

TBMM Araştırma Komisyonu Raporu (2018). https://www.tbmm.gov.tr/develop/owa/komisyon tutanaklari.goruntule?pTutanakId=2044 (Erişim Tarihi: 16.05.2018)

Terzi, Ş. (2008). Üniversite ögrencilerinin psikolojik dayanıklılıkları ve algıladıkları sosyal destek arasındaki ilişki. Türk Psikolojik Danışma ve Rehberlik Dergisi, 3(29), 1-11.

Törrönen, J., Roumeliotis, F., Samuelsson, E., Kraus, L.ve Room, R. (2019). Why are young people drinking less than earlier? Identifying and specifying social mechanisms with a pragmatist approach. International Journal of Drug Policy, 64, 13-20.

TUBIM (Türkiye Uyuşturucu ve Uyuşturucu Bağımlılığı İzleme Merkezi), (2012). www.sck.gov.tr/oecd/2012\%20T\%C3\%BCrkiye\%20Uyu\%C5\%9Fturucu\%20Raporu. (Erişim: 23.11.2018) 
TUBiM, (2014). Türkiye Uyuşturucu Raporu, (Erişim tarihi: 24.02.2018) http://www.kom.pol.tr/tubim/sayfalar/t\%c3\%bcrkiye-uyu\%c5\%9fturucu raporu.aspx.

Turhan, E., İnandı, T., Özer, C. ve Akoğlu, S. (2011). Üniversite öğrencilerinde madde kullanımı, şiddet ve bazı psikolojik özellikler. Türkiye Halk Să̆glı̆̆l Dergisi, 9(1), 33-44.

Uludağlı, N. P. ve Sayıl, M. (2009). Orta ve ileri ergenlik döneminde risk alma davranışı: Ebeveyn ve akranların rolü. Türk Psikoloji Yazıları, 12(23), 14-24.

Ünlü, A. ve Evcin, U. (2014). Evaluation of prevalence of substance use, risk and protective factors between 2008 and 2010 in Bağcllar, İstanbul. Anadolu Üniversitesi Sosyal Bilimler Dergisi, 14(3), 127-140.

Unlu, A. (2009). The impact of social capital on youth substance use. Doctoral dissertation, University of Central Florida Orlando, Florida.

Uzun, S. (2017). Lise öğrencilerinin madde bağımlılı̆̆ı profilleri, madde bağımlılı̆̆ıdan korunma konusundaki öz yeterlikleri ve önleme konusundaki görüşleri. Yayınlanmamıs yüksek lisans tezi, Cumhuriyet Üniversitesi Sağlık Bilimleri Enstitüsü, Sivas.

Wills, T. A. ve Yaeger, A. (2003). Family factors and adolescent substance use: Models and mechanisms. American psychological society, 12 (6), 222226.

Yardımcı, F. ve Başbakkal, Z. (2010). Ortaokul Özyeterlilik Ölçeğinin Geçerlilik ve Güvenilirlik Çalışması. Anadolu Psikiyatri Dergisi, 11, 321-326.

Yıldız, E. U. (2009). İzmir liselerinde sigara, alkol, madde kullanım yaygınlığı, hazırlayıcı ve koruyucu faktörler. Yayımlanmamış doktora tezi, Ege Üniversitesi Sosyal Bilimler Enstitüsü, İzmir.

Yılmaz, D. ve Türkkahraman, M. (2014). Önleme çalısmalarında Antalya ili lise ve üniversite ögrencilerinde madde kullanımının ve risk etkenlerinin incelenmesi. Journal of Educational Science, 2(3), 1-20. http://dergipark.gov.tr/jedus/issue/16126/168712

Yılmaz, H. ve Sipahioğlu, Ö. (2012). Farklı risk gruplarındaki ergenlerin psikolojik sağlamlıklarının incelenmesi. İlköğretim Online, 11(4), 927944.

Zullig, K. J., Teoli, D. A., ve Valois, R. F. (2014). Emotional self-efficacy and alcohol and tobacco use in adolescents. Journal of drug education, 44(12), 51-66. 


\section{Kaynakça Bilgisi / Citation Information}

Tilim, E. ve Murat, M. (2019). Ergenlerde madde bağımlılı̆̆ından korunmaya ilişkin özyeterlik ile akran baskısı, kendini ifade edebilme becerisi ve psikolojik sağlamlık arasındaki ilişki. OPUSUluslararası Toplum Araştırmaları Dergisi, 14(20), 929-955. DOI: 10.26466/opus.608229 